\title{
Türk - Alman İlişkilerinin Yansımaları: Almancaya Geçen Türk Devlet Sistemi Unvanları
}

\section{Reflections of Turkish - German Relations: Titles of Turkish State \\ System Loaned to German}

\section{Ümit Soylu ${ }^{1}$}

Başvuru Tarihi: 09.04.2019

Kabul Tarihi: 13.09.2019

Öz

Türk ve Alman uluslarının resmî ilişkilerde bulunması yaklaşık 250 yıl öncesine, Osmanlı Devleti ile Prusya Devleti arasında gerçekleşen antlaşmalara dayanır. Bu süre içinde Osmanlı ve Prusya (sonradan Alman İmparatorluğu) siyasi, askerî ve ticari alanda yakın ilişkilerde bulunmuştur. Söz konusu ilişkiler sonucunda her iki ülke diğerinden kendisi için yeni olan bilgiler öğrenerek bu bilgilerin adlarını dillerine katmıştır. Bu dil alısverişinin en önemli ürünlerinden biri unvanlardır. Bugün Türkçede Almanca unvanların bulunması gibi Almancada da Türkçe unvanlar bulunur. Almanya'nın Türklerle ilişkisi çoğunlukla Osmanlı dönemine dayandiğı için Almancadaki Türkçe unvanların çoğunluğu Osmanlı devlet sisteminde kullanılan unvanlar olmuştur. Unvanların tespiti için bu çalışmada -yazılış tarihi Osmanlı Devleti'nin son dönemine rastlayan- Almanca ansiklopedik sözlükler, güncel Almanca sözlükler ve Türkçenin Almancaya verintileri üzerine hazırlanmış çalışmalar kullanılmıştır. Bütün bu çalışmalarda yüzden fazla Türkçe unvan belirlenmiş, unvanlarmn çoğunlukla siyasi-askerî alanda olduğu görülmüştür. Dolayısıyla bu verintilerin, başta Osmanlı Devleti olmak üzere Türk devletleri ile Prusya/Almanya arasındaki siyasi-askerî ilişkilerin doğal sonucu olduğu söylenebilir.

Anahtar Kelimeler: Unvan, Sözlük, Verinti, Türk-Alman İlişkileri

\begin{abstract}
Official relations between Turkish and German nations began 250 years ago, as a result of treaties signed between The Ottoman Empire and The Kingdom of Prussia. During this period, The Ottoman Empire and The Kingdom of Prussia (subsequently The German Empire) initiated diplomatic, commercial and military relationships. Through those links, both countries acquired new knowledge from one another and consequently assimilated new nouns into their own languages. One of the most significant examples of this word borrowing process is found in titles.
\end{abstract}

${ }^{1}$ İstanbul Aydın Üniversitesi Fen Edebiyat Üniversitesi, soyluumit@hotmail.com, ORCID: 0000-0002-3581-4122 
Up to this day, German titles appear in Turkish and Turkish titles in German. Since German relations with Turkish were mostly formed during the Ottoman period, almost all Turkish titles in German belong to its state system. So as to find those titles, this study uses certain German encyclopedic lexica -written in the late period of The Ottoman Empire-, contemporary German dictionaries and certain works on Turkish loaned words to German. Consequently it establishes that more than one hundred Turkish titles are found in German, mostly related to politics and military. There is a strong case that they have resulted from the official relations between Turkic states, notably The Ottoman Empire, and Prussia/Germany.

Keywords: Title, Dictionary, Loaned Word, Turkish-German Relations

\section{Giriş}

Haçlı seferleri ve Avrupa savaşları sırasındaki karşılaşmalar dikkate alınmazsa Türklerin Almanlarla ilk resmî ilişkileri 250 yıldan biraz fazla bir zaman öncesine dayanmaktadır. $\mathrm{Bu}$ sürede önce Prusya'yla, Alman Birleşimi (Deutsche Einigung) sonrasında da Almanya'yla girilen ilişkiler siyasi ve askerî alanda gerçekleşmiştir. Söz konusu ilişkiler sonucunda her iki ülkenin devlet sisteminde kullanılan unvanlar karşılıklı olarak tanınır olmuş, Almancada Türkçe unvanlar ve Türkçede Almanca unvanlar kullanılmıştır. Türkçede kayzer, general, dekan, doçent gibi Almanca unvanlar bulunurken Almancada da sultan, paşa, ağa, bey gibi Türkçe unvanlar mevcuttur.

Bugün Türkçenin ilişkiye girdiği dillerle yaptığ 1 sözcük alışverişi üzerine birçok çalışma mevcuttur, ancak bu çalışmaların büyük çoğunluğu diğer dillerden Türkçeye alıntılar üzerinedir. Verintilerin alıntılara göre daha zor belirlenmesi nedeniyle Türkçenin verintileri üzerine yapılan çalışmalar kısıtlıdır. Çünkü verintilerle ilgili çalışmalar birçok sözlüğün ve çalışmanın incelenmesini gerektirir. Buna bağlı olarak yapılan alan taramasında Almancadaki Türkçe unvanlar üzerine özel çalışmaların bulunmadığı görülmüştür. Bu unvanları saptamak, Türkçenin Almanca üzerindeki siyasi-askerî etkisini belirlemiş olacaktır.

\section{Türk - Alman Siyasi ve Askerî Ilişkilerine Kısa Bakış}

Tarih boyunca büyük savaşlarda birbirine karşı doğrudan taraf olmamış Türk ve Alman uluslarının ilk karşılaşması, Haçlı seferlerine dayanmaktadır. Bu bağlamda ilk önemli belge olarak kabul edilen Historia Hierosolymitana adlı kronik, Türklerin Almanlarla topluluk olarak ilk karşılaşmasını konu edinir (Kula, 1992, s. 15). Haçlı seferlerinde baş gösteren Türk endişesi ve karşıtllğı, Osmanlı Devleti'nin İstanbul'u almasılyla önce Türk korkusuna dönüşmüş, daha sonra da Viyana kuşatmasının başarısızlığı nedeniyle Türkleri küçümseme hâlini almıştır (Mora, 2011, s. 26). Ancak bir yandan da bu küçümseme, Avrupalılarda, yenilmez olmadığı anlaşılan Türkleri tanıma merakını doğurmuştur.

Osmanlı Devleti’nin Almanlarla siyasi anlamdaki ilk ilişkisi Prusya dönemine dayanmaktadır. Öncesinde yapılan mektuplaşmalar dikkate alınmazsa, Osmanlı ve Prusya'nın ilk resmî ilişkisi 1761 yllında imzalanan Dostluk, Gemicilik ve Ticaret Antlaşması'dır (Alkan, 2015, s. 35, 39). 
Böylece Osmanlı ve Prusya arasındaki siyasi ve ticari ilk adım atılmıştır. Bu antlaşmayı 1763 yılında Ahmed Resmî Efendi'nin, beraberinde 70-73 kişilik bir heyetle birlikte Osmanlı Devleti tarafından elçi olarak Prusya'ya gönderilmesi izlemiştir (Tosun, 02 Aralık 2013). O yıllarda başlayan ilişkiler, iki ülkeyi, 1790 yılında Rusya ve Avusturya’ya karşı ittifak kurmaya kadar götürmüştür (Beydilli, 1981, s. 62). Çünkü Rusya ve Avusturya'nın Avrupa'da yayılması ya da güçlenmesi hem Osmanlı hem de Prusya açısından bir tehlikedir. Böylece 1761 yılında başlayan ticari ilişkiler 1790 yılında siyasi ve askerî olarak da devam etmiş, Osmanlı ve Prusya Avrupa'da iki önemli müttefik hâline gelmiştir. Bu ittifak, Osmanlı'nın Hristiyan bir devletle yaptığ birlikte saldırı ve savunma niteliğindeki ilk anlaşma olması açısından da önemlidir (Beydilli, 1981, s. 62).

Prusya’yla yakınlaşmanın ilk önemli yansıması 2. Mahmut dönemine denk gelir. 1827 yılında Fransa, İngiltere ve Rusya'nın ortak donanmasının Osmanlı donanmasını yakması, Yunanistan'ın bu devletlerce tanınması ve 1830 yılında Fransa'nın Cezayir’i işgal etmesi; padişahın, Batılı tarzda modern bir ordu kurmak için Prusya'nın yardımına başvurmasına neden olmuş ve 1835-1839 yılları arasında görev yapacak olan Helmut von Moltke liderliğindeki askerî bir kurul Osmanlı Devleti’ne gelmiştir (Albayrak, 1995, s. 2). Kurul, Moltke ve bir diğer uzmandan oluşan iki kişilik bir kuruldur (Özgüldür, 1993, s. 298). Bu kurulun, daha ileriki dönemlerde Alman askerlerinin Osmanlı ordusunda yüksek rütbelere yükselmesi konusunda ilk adım olarak nitelendirilmesi mümkündür (Alkan, 2015, s. 41).

Osmanlı-Prusya ilişkileri, askerî dışında ticari anlamda da 19. yüzyıl ortalarında gelişmeye başlamıştır. 1833 yılında Alman devletleri arasında imzalanan Alman Gümrük Birliği (Deutscher Zollverein) antlaşmasının ardından Osmanlı-Prusya ticari ilişkileri gelişmiş, birliğe bağlı devlet tüccarları Osmanlı topraklarında en çok müsaadeye mazhar devlet tüccarı statüsüne sahip olmuşlardır (Albayrak, 1995, s. 2).

1871 yılında gerçekleşen Alman Birleşimìnin ardından Osmanlı-Almanya ilişkileri yeni bir döneme girmiştir. Alman Şansölye Otto von Bismark, Osmanlı’yla ilişkilerini bir nevi dondurarak Fransa'yı Avrupa'da yalnız bırakma amacıyla Rusya ve Avusturya'ya yaklaşırken; şehzadeliği dönemindeki Prusya seyahatlerinde Alman sanayisi ile ordusunun gücünü gören 2 . Abdülhamit, 1876 yılında tahta çıtıktan sonra, Osmanlı için bir tehlike oluşturmayacak Almanya'ya yakınlaşma ihtiyacı duymuştur (Albayrak, 1995, s. 3-4). 1877-1878 Rus savaşından yenilgiyle çıkan orduyu güçlendirmek için Almanya'dan askerî bir kurul istemiş, Berlin Kongresinden sonra tutumunu değiştiren Almanya ise kendi çıkarı açısından yararlı olabilecek bu teklifi geri çevirmeyerek 1882 yılında dört kişilik bir kurulu (bir kurmay subay, birer topçu, süvari ve piyade subayı) ve daha sonra eğitimci olarak Binbaşı Colmar von der Goltz’u Türkiye’ye göndermiştir (Çalık, 1996, s. 771-773). Goltz göreve başladıktan sonra Almanya'dan silah ve mühimmat alınmış, 1890’lı yılların sonunda Alman silah fabrikaları Osmanlı pazarını tamamıyla ele geçirmiştir (Ortaylı, 1983, s. 104). Aynı dönemde Osmanlı’ya gelen Alman askerî uzmanların sayısı da gittikçe arttığından dolayı Almanların Osmanlı ordusu üzerindeki etkileri büyümüştür (Albayrak, 1995, s. 5). Böylece Osmanlı Devleti’ndeki Fransız hayranlı̆̆ yerini yavaş yavaş Alman hayranlığına bırakmış ve özellikle askerî sınıf Alman etkisi altına girmeye başlamıştır (Zengin, 2013, s. 50). 
Askerî alanda başlayan yakınlaşma, 1888 yılında 2. Wilhelm'in Alman kayzeri olmasıyla siyasi ve ticari alana da yayılmıştır. Bismarck'ı istifaya zorlayan kayzerin 1889 yılında İstanbul'a yaptığı ziyaret sonucunda Almanya'nın Osmanlı’ya olumlu bakış açısı kesinlik kazanmıştır. Bu ziyaretin iki önemli sonucu vardır: 1890 yılında iki ülke arasında bir ticaret antlaşmasının imzalanması ve Bağdat demiryolunun Konya'ya uzatılması ayrıcalığının Almanlara verilmesi (Alkan, 2015, s. 44). Kayzer 1898 yılında İstanbul'a ikinci bir ziyaret gerçekleştirmiştir. İkinci seyahatine Kudüs ve Şam'ı da ekleyen kayzerin yaptığı konuşmalar, Almanya'nın Müslümanların dostu olduğunu açıkça göstermiştir (Albayrak, 1995, s. 7; Alkan, 2015, s. 44). Bu ziyaretlerle hem ticari hem de siyasi olarak Osmanlı ve Almanya birbirine yakınlaşmıştır.

Osmanlı'da artan Alman askerî etkisi bu kadarla kalmamış; 1912-1913 Balkan savaşlarında yenilgiye uğrayan Osmanlı Devleti, ordusunun yeniden düzenlenmesi için yine Almanya'ya başvurmuştur (Özgüldür, 1993, s. 303-304). Osmanlı'nın talebi kabul görmüş ve üçüncü kez olmak üzere General Liman von Sanders önderliğinde bir kurul Osmanlı Devleti'ne gönderilmiştir. 1913 yılında 42 subayla birlikte İstanbul'a gelen Sanders, 1. Kolordu komutanlığına atanmıştır (Sanders, 1999, s. 11, 14). Bu ilişkiler, iki ülkenin 1. Dünya Savaşı’nda müttefik olmasına kadar gitse de savaşın kaybedilmesi ilişkileri zorunlu olarak durdurmuştur.

Osmanlı Devleti'nin yıkılıp Türkiye Cumhuriyeti'nin kurulması ve Almanya'nın 2. Dünya Savaşı'na girmesi, iki ülke arasındaki yakın ilişkilerin yeniden başlamasına engel olmuştur. Uzun süreli bu durgunluk, 1961 yılında Almanya'nın Türkiye'den işçi almaya başlamasıyla sona ermiştir. 1970 yılından sonra devamlı ikamete dönüşen Türk göçmenlerin durumu, bugün Türkiye ve Almanya arasındaki ilişkilerde temel başlıklardan biridir.

\section{Unvanların Tespitinde Kullanılan Yöntem}

Alman devletleriyle girilen ilişkilerin sonucu olan Türkçeden verinti unvanların bir nedeni de ülkemizde görev yapan Alman askerî görevlilerin yazdıkları mektup, rapor ve anı kitaplarında bu unvanların kullanılmış olmasıdır. Dolayısıyla Türkçeden Almancaya geçen unvanlar dönemin ansiklopedik sözlüklerine girmiş, bazıları günümüzdeki modern sözlüklerde de yer edinmiştir. Bu nedenle, Almancaya geçen Türkçe unvanların tespiti üzerine olan bu çalışmada, (ansiklopedik) sözlüklerin ve verintiler üzerine hazırlanmış çalışmaların taranması yöntem olarak kullanılmıştır. Seçilen sözlük ve çalışmaları üç grupta değerlendirmek gerekir:

İlk grup, döneminin en önemli sözlükleri olarak kabul edilen Brockhaus (1911), Herder (1854-1857), Meyer (1902-1908) ve Pierer (1857-1865) gibi ansiklopedik çalışmalardan oluşmaktadır. Söz konusu sözlüklerin özelliği, 19. yüzyıl ortası ve 20. yüzyıl başı arasında, yani Osmanlı Devleti’nin henüz ayakta olduğu dönemde yazılmış olmasıdır.

İkinci grubu ise Almancanın günümüzde kullanılan sözlükleri oluşturmaktadır: Duden Online Wörterbuch, Wahrig Fremdwörterlexikon ve Wissen Wörterbuch. Sözcüklerin en güncel şekillerinin alınması amacıyla söz konusu sözlüklerin çevrimiçi sürümleri kullanılmıştır.

Son grup ise Karaağaç'ın (2008) Türkçenin verintileri üzerine hazırladığı verintiler sözlüğü ile Keleş'in (2003) Almancadaki Türkçe sözcüklerin listesine yer verdiği makalesi gibi Türkçe çalışmaları kapsamaktadır. 
Sözcüklerin Türkçe şekilleri, genel itibariyle, Türk Dil Kurumunun sitesinde çevrimiçi olarak bulunan Güncel Türkçe Sözlük'ten ve Tarih Terimleri Sözlüğ̈̈’nden (1974) alınmıştır.

Sözcüklerin, taranan sözlüklerin herhangi birinde Türkçe kökenli olarak bulunması ya da başka bir dilden girmesine rağmen tanımında Türk devletlerinde kullanılan bir unvan olarak geçmesi tespit için esas alınmıştır. Dolayısıyla bu sözlüklerde sözcügün kökeni olarak Türkçenin yanı sıra Arapça, Farsça, Yunanca, Sırpça gibi diller verilmiş olabilir.

Çalışmaya Türk devlet sisteminde kullanılan unvanlar alınmıştır. Günlük hayatta var olan bazı unvanlar resmî olarak kullanılmadığı için listeye dâhil edilmemiştir. Her sözcüğün yanında o sözcüğün Almancada bulunan bütün değişkeleri bir arada gösterilmiş, ardından tespit edildiği çalışmalar listelenmiştir. Listeleme sırasında, çevrimiçi sürümleri www.wissen.de adlı internet sitesinde bulunduğundan dolayı Wahrig Fremdwörterbuch için Wissen F. ve Wissen Wörterbuch için Wissen W. kısaltmaları kullanılmıştır. Diğer sözlük ve çalışmalar yazar ya da yayımcı adlarıyla belirtilmiştir. Sözlük adlarından sonra ise o sözlükte bulunan değişkeler ve -varsa- değişkelerin bulunduğu cilt sayıları ile sayfa numaraları verilmiştir. Birden fazla değişkesi olan sözcüklerde sadece tanımın bulunduğu maddenin ya da -bütün değişkeler tanımlanmışsa- alfabetik sıradaki ilk maddenin sayfa numarası gösterilmiştir. Wahrig, Wissen ve Duden sözlüklerinin çevrimiçi sürümleri kullanıldığı için bu sözlüklerin geçtiği yerlerde sayfa numaraları verilmemiştir.

Unvanların tanımlarındaki özel durumlar ve madde başlarıyla ilgili ayrıntılar dipnotlarda açıklanmıştır. Unvanlardan türeyen, onlarla birleşik ad oluşturan ya da ilintili olan sözcükler de değişkeleriyle birlikte İ.S. (ilintili sözcükler) kısaltmasıyla yine dipnotlarda listelenmiştir.

\section{Almancaya Geçen Türk Devlet Sistemi Unvanları²}

Yöntem bölümünde belirtilen (ansiklopedik) sözlük ve çalışmaların taranması sonucunda Alman dilinde tespit edilen Türk devlet sistemi unvanları, unvanların tespit edildiği çalışmalar ve gerekli açıklamalar aşağıdaki gibidir:

1. $\operatorname{Ağa}>\operatorname{Ag}(h) a^{3}$

Brockhaus $(A g(h) a)(1 / 20)$, Duden $(A g a)$, Herder $(A g(h) a)(1 / 66)$, Karaağaç $(A g(h) a)$, Keleş (Aga) (126), Meyer (Agha) (1/169), Pierer $(A g(h) a)(1 / 174)$, Wissen F. $(A g(h) a)$, Wissen W. $(A g a)$.

2. Akıncı > Akindschis (çoğul)

Pierer (Akindschis) (1/244).

3. Alemdar $>$ Alemdar ${ }^{4}$

Brockhaus (Alemdar) (1/38), Pierer (Alemdar) (1/285).

\footnotetext{
Açıklama yapılan maddelerdeki Almanca tanımlar bu makalenin yazarı tarafından Türkçeye aktarılmıştır.

3 İ.S.: Aga der Dschebedschi, Aga der Topdschi (/Topdschilar Ag(h)a), Aga Khan, Amakdar-Agasi, Astalar-Aga, Babi-Scadel-Ag(h)a(ssi) (/Babi-SeadetAgalar), Birun-Agalar, Buluk-Agalar, Capi (/Kapi)-Aga (/Kapu-Agassi), Chadim-Agassi, Dârus-Saâdet-Aghassi, Endern-Agalar, Fazna-Agasi, Galiondschi-Aga, Gesandar-Aga, Hasteler-Agasi, Ifaga, Imbrikdar-Aga, Janitscharen-Aga (/Jenitscheri Agassi), Kasnadar-Aga, Kiarkuk-Odaz Agasi, Kirdar-Aga, Kol-Aghassi, Kislar-Aga(ssi) (Kizlar-Agassi/Kyslar-Aghassi/Kyzlar-Agassy), Kuschdschi Aga, Nikinotar-Aga, Odschak Agalar, Rikiabdar (/Rkiabtar)-Aga, Saliktar (/Seliktar) Aga, Schat-Zedeler-Agasi, Schemnegi Aga, Sera-Agassi, Serai-Aga, Seraidar-Agassi, Serhadd-Aga, Silihdar-Aga(lar), Sipahi-Agalar, Tschokadar-Agassi.

4 İ.S.: Alem.
} 
4. Ametçi ${ }^{5}>$ Amedschi / Ametschy ${ }^{6}$

Pierer (Amedschi/Ametschy) (1/415).

5. Asker $>$ Asakiri (çoğul) / Askari(s) (çoğul) / Askeri (çoğul) ${ }^{7}$

Brockhaus (Askari) (1/108), Keleş (Askaris) (126), Meyer (Asakiri) (1/840), Pierer (Askeri) $(1 / 820)$.

6. Atmacaci $^{8}>$ Atmadschi

Pierer (Atmadschi) (1/898).

7. Âyan $>$ Ayan $^{9}$

Pierer (Ayan) (2/107).

8. Azap > Asab / Azab / Azap ${ }^{10}$

Herder (Asab) (1/279), Pierer (Asab/Azab/Azap) (1/795).

9. Balabanc1 > Balabanschi

Pierer (Balabanschi) (2/231).

10. Baltac1 > Baltadschi $(\mathrm{y})^{11}$

Meyer (Baltadschi) (2/312), Pierer (Baltadschiy) (2/256).

11. Baş ${ }^{12}>$ Basch- / -baschi ${ }^{13}$

Brockhaus (Basch) (1/157), Herder (Basch) (1/418), Meyer (Basch) (2/416), Pierer (Basch/Baschi) (2/367).

12. Bay $>\operatorname{Ban}(\text { us })^{14}$

Duden (Ban(us)).

5 Güncel Türkçe Sözlük'te bulunmayan sözcüğün Türkçe şekli Tarih Terimleri Sözlü̆ğ̈̉ndeki (1974) ametçi maddesinden alınmıştrr.

6 İ.S.: Amed (d)schi Effendi.

7 İ.S.: Lewendtschiftlik Askeri.

8 Güncel Türkçe Sözlük'te bulunmayan sözcügün Türkçe șekli Tarih Terimleri Sözlüğündeki (1974) atmacacıbașı maddesinden alınmıștır.

9 İ.S.: Ayan Birun, Ayan Enderun.

10 İ.S.: Asab Köschk, Kurekdschi Asab.

11 İ.S.: Baltadschiylar Kiajassi, Süfli Baltadschi.

${ }^{12}$ Başs sözcüğü doğrudan bir unvan olmasa da bu sözcükle yapılan birleşik sözcükler arasında birçok unvan bulunmaktadır. Nadiren -bascha şekli de görülmektedir.

${ }_{13}$ İ.S.: Agati-Baschi, Alimestar-Baschi, Ambadar-Baschi, Arra (Spiur/Zior)-Baschi, Balikdschi-Baschi, Basarkhan-Baschi, Basch-Beg, Basch-Bog(h), BaschDefterdar, Basch-Eski, Basch-Kadun (/-Kadyn), Basch-Kalemie, Basch-Kapu Kiaja, Basch-Kapudschi (/Kapudschi-Baschi), Basch-Kapu Oglani, BaschKaru Kulukdscha, Basch-Kiatib, Basch-Terdschuman, Basch-Tschausch (/Tschausch-Baschi), Basch-Tschadir, Basch-Tschokadar, Basch-Wekil, BaschiBosuk(s) (/-Bozuk(s)/Baschibosuk), Begibaschi, Berber-Baschi (/-Baschy), Bim (/Bin)-Baschi, Boluk (/Bölük/Buluk)-Baschi, Bombardschi-Baschi, Bostandschi-Baschi (/-Baschy), Capidschi (/Capigi/Kapidschi)-Baschi, Chacham-Baschi, Chiler-Baschi, Deli Baschi, Dogandschi-Baschi, Ekmekbaschi, Ferrasch-Baschi, Gorschi-Baschi, Gugom-Baschi, Hasnadar (/Kasnadar)-Baschi, Hakim (/Hekim)-Baschi, Halwa-Baschi, Hamamdschi-Baschi, Harambascha, Imbrahar-Baschi, Jüs-Baschi, Kaftandschi-Baschi, Kaim-Baschi, Kambaradschi (/Kumbaradschy)-Baschi, Kar(a)van (/Kerwan)-Baschi, Käsab-Baschi, Kaschan-Baschi, Katzerzi-Baschi, Kawass-Baschi, Khaberdschi-Baschi, Kilar (/Kilardschi)-Baschi, Kindar-Baschi, Kischandschi (/Nischandschi)-Baschi, Kisilbasch (/Kisil-Bascha), Kodscha (/Kodja)-Baschi, Kohwedschi-Baschi, Kodscha-Baschi, Konakdschi-Baschi, Kurtschi-Baschi, Kurzi-Baschi, Laghundschi-Baschi, Lalabaschi, Londscha-Baschi, Mehmander (/Mihmandar)-Baschi, Meman-Baschi, Mescheldar-Baschi, MonadschiBaschi, Munedschim-Baschi, (Kas/Khaß)Oda-Baschi, Onbaschi, Orta-Baschi, Odontar-Baschi, Simazen-Baschi, Solakbaschi, Sou-Baschi, Tapigi-Baschi, Tesk(j)eredschi-Baschi, Thorbaschi, Topdschi (/Toptschi/Topschjy)-Baschi, Tournadschy-Baschy, Tschamaschir-Baschi, Tschikkias-Baschi, TuchemalBaschi, Tuffendschi-Baschi, Zagargi (/Zigori Baschi), Zalizi Melektar Baschi, Zegber-Baschi.

${ }^{14}$ Duden sözlüğünde (özellikle Hirvatistan ve Güney Macaristan'da) vali, bölge yöneticisi șeklinde tanımlanan Ban ve Banus maddelerinde sözcüğün kökeni olarak Türkçe bay (zengin adam) sözcüğü verilmiştir. Sözcüğün bu anlamı Güncel Türkçe Sözlük’te sözcüğün birinci maddesinde geçmektedir. 
13. Bayraktar ${ }^{15}>$ Bairakdar / Bairaktar ${ }^{16}$

Brockhaus (Bairaktar) (1/141), Herder (Bairaktar) (1/385), Meyer (Bairakdar) (2/281), Pierer (Bairakdar) (2/221).

14. Beşli ${ }^{17}>$ Bechlis (çoğul) / Beschli / Beslis (çoğul) / Boschli

Herder (Bechlis) (1/450), Pierer (Bechlis/Beschli/Beslis/Boschli) (2/461).

15. Bey > Beg(h) / Bei / Bej / Bey ${ }^{18}$

Brockhaus (Beg/Bei/Bej) (1/173), Duden (Beg/Bei/Bey), Herder (Bei/Beg) (1/459), Karaağaç (Bei/Beg) (105), Keleş (Bei/Beg) (126), Meyer (Beg/Bei/Bey) (2/804), Pierer (Beg(h)) (2/487), Wissen F. (Bei/Beg/Bey).

16. Bostanci ${ }^{19}>$ Bostandschi $^{20}$

Brockhaus (Bostandschi) (1/246), Herder (Bostandschi) (1/625), Meyer (Bostandschi) $(3 / 259)$.

17. Buzcu $>$ Bosdschi

Pierer (Bosdschi) (3/113).

18. Çavuş > Tschausch / Tschiaus ${ }^{21}$

Duden (Tschausch), Herder (Tschausch) (5/529), Karaağaç (Tschausch) (183), Keleş (Tschausch) (129), Meyer (Tschausch) (19/765), Pierer (Tschausch/Tschiaus) (17/883).

19. Çorbac1 ${ }^{22}>$ Tschor Baschi

Pierer (Tschor Baschi) (17/905).

20. Çuhadar $>$ Thoadar / Tschohadar / Tschokadar ${ }^{23}$

Pierer (Thoadar) (17/530), Meyer (Tschohadar/Tschokadar) (19/780).

21. Danişment ${ }^{24}>$ Danischmend

Pierer (Danischmend) (4/731).

\section{Day1 > Dai / Daji / Dei / Dey}

Brockhaus (Dai/Dei) (1/401), Herder (Dei/Dey) (2/306), Meyer (Daji/Dei/Dey) (4/588), Pierer (Dey) (5/98).

23. Defterdar $>$ Defterdar / Tefterdar ${ }^{25}$

Brockhaus (Defterdar) (1/401), Herder (Defterdar) (2/304), Meyer (Defterdar), Pierer (Defterdar/Tefterdar) (17/317).

\footnotetext{
${ }^{15}$ Bayraktar maddesinde Brockhaus, Herder, Meyer ve Pierer sözlüklerinde asıl olarak Alemdar Mustafa Paşa anlatılmıştır. Ancak tanımdan önce sözcüğün Türkçe anlamı bayrak taşıyıcısı olarak verilmiştir.

16 İ.S.: Bairak.

${ }^{17}$ Sözcük, Pierer sözlüğünde hem tekil (Beschli) hem çoğul (Bechlis/Beslis) şekliyle bulunmaktadır.

${ }^{18}$ İ.S.: Alaibeg, Atabeg (/Atabek), Basch-Beg, Beglerbeg (/Beilerbei), Beglik (/Beilik), Beglikdschi Efendi, Begüm, Bergamotte, Derebeg, Hukumet-Beg, Kaimakam-Beg, Kapudan-Bey, Kiafa Kifaja-Bey, Kiaja (/Kjaja)-Beg, Kjetchuda-Bey, Ös-Beg (>Uzbek), Riala-Bei, Sandschak-Beg.

${ }^{19}$ Sözcük, Pierer (3/127) sözlüğunde Bostandschi şekliyle Bostan maddesinde açıklanmıştır.

${ }^{20}$ İ.S.: Bostan, Bostandschi-Baschi (/-Baschy).

${ }^{21}$ İ.S.: Alai Tschausche, Basch-Tschausch (Tschausch-Baschi), Gedekli Tschausch, Kulagus-Tschausch, Orta-Tschausch.

${ }^{22}$ Sözcük, Pierer sözlüğünde iki sözcükten oluşan bir unvan olarak verilmiştir: Tschor (Çor) + Baschi (-bacı). Baschi, baş sözcüğünün Almanca yazımı -baschi ile aynıdır. Sözcüğün bu şekli muhtemelen yazım yanlışıdır.

${ }^{23}$ İ.S.: Basch-Tschokadar, Tschokadar-Agassi.

${ }^{24}$ Sözcüğü Meyer (4/498) sözlüğünde Danişmentliler Beyliği olarak açıklanmıştır.

${ }^{25}$ İ.S.: Basch-Defterdar, Defterchan, Defterdar-Kapußi.
} 
24. Deli $^{26}>$ Deli $^{27}$

Herder (Deli) (2/312), Meyer (Deli) (4/610), Pierer (Deli) (4/814).

25. Dilmaç ${ }^{28}>\operatorname{Dolmetsch}(\mathrm{er})^{29}$

Brockhaus (Dolmetsch(er)) (1/447), Karaağaç (Dolmetsch(er)) (246), Keleş (Dolmetsch(er)) (126), Meyer (Dolmetsch(er)) (5/93), Wissen F. (Dolmetsch(er)), Wissen W. (Dolmetsch(er)).

26. Efendi $>$ Ef(f)endi ${ }^{30}$

Brockhaus (Ef(f)endi) (1/482), Duden (Ef(f)endi), Herder (Ef(f)endi) (2/500), Karaağaç (Ef(f)endi) (274), Keleş (Ef(f)endi) (126), Meyer (Ef(f)endi) (5/385), Pierer (Ef(f)endi) (5/484), Wissen W. (Ef(f)endi).

27. $\operatorname{Emin}>\operatorname{Emin}(\mathrm{i})^{31}$

Duden (Emin), Meyer (Emini) (5/756), Pierer (Emini) (5/674), Wissen F. (Emin).

28. Emîr > Amir / (E)Mir ${ }^{32}$

Meyer ((E)Mir) (5/757), Pierer (Amir/Emir) (5/674).

29. Ferik $>$ Ferik $^{33}$

Brockhaus (Ferik) (1/570), Herder (Ferik) (2/686), Meyer (Ferik) (6/431), Pierer (Ferik) (6/196).

30. Gazi > G(h)asi / G(h)azi ${ }^{34}$

Duden (Gazi/Ghasi), Meyer (G(h)asi/G(h)azi) (7/815-816), Pierer (Gazi) (7/23).

31. Gedikli > Gedekli ${ }^{35}$

Pierer (Gedekli) (7/38).

32. Hakan / Han / Kağan > Chakan / (Il)Chan / Khak(h)an / (Il)Khan ${ }^{36}$

Brockhaus ((Il)Chan/Chakan/Khan) (1/324), Duden (Chan/Khan), Herder (Khan), Karaağaç (Chan/Khan) (346), Keleş (Khan) (127), Meyer (Chakan/Chan/Khan) (3/859), Pierer (Chakan/Chan/Khak(h)an/(Il)Khan) (9/458), Wissen F. (Chan/Khan), Wissen W. (Chan/Khan).

33. Hâkim ${ }^{37}>$ Hakim / Hekim ${ }^{38}$

Herder (Hakim) (3/207), Meyer (Hakim/Hekim) (8/639), Pierer (Hakim) (7/861).

\footnotetext{
${ }^{26}$ Almanca sözlüklerde (eskiden) sadrazam ve paşaların özel koruması ya da gönüllü bir atlı asker anlamında kullanılan sözcüğün bu anlamı Tarih Terimleri Sözlüğ̈̈’ndeki (1974) deli maddesinde bulunmaktadır.

${ }^{27}$ İ.S.: Deli Baschi.

${ }^{28}$ Sözcük, Herder (2/423) sözlüğünde Dolmetsch şekliyle dolmetschen maddesinde verilmiştir.

${ }^{29}$ İ.S.: dolmetchen, Dolmetscherin.

${ }^{30}$ İ.S.: Amed(d)schi Effendi, Beglikdschi Efendi, Bey Efendi, Hakim (/Hekim)-Ef(f)endi, Hanum Efendi, Imam-Ef(f)endi, Estambul (/Istambol/(I)Stambul) Efendi(si), Janitscharen-Effendi, Mektubdschi Efendi, Mühürdar Efendi, Pascha Efendi, Reis-Ef(f)endi.

${ }^{31}$ İ.S.: Alai-Emini, Bahar-Emini, Fetfa(h) (/Fetwa)-Emini, Sanduk-Emini, Schehr-Emini, Sergi-Emini, Sur (/Surre)-Emini, Terfauch (/Tersaneh/Terzana)Emini, Sarbhane (/Zarphana)-Emini.

32 İ.S.: Emir-Achor (/-Ochur) (/Imbrachor/Imbrochor/Imra(c)hor), (E)Mir-Alem, Emir-Hadsch(i), Emir ul Muminin, Mir Ali, Mir-Alai, (E)Mir-i-Liwa, Mir-i-Miran, (E)Mirije, Miri, Sur-Emir, Umara.

${ }^{33}$ İ.S.: Ferik Pascha.

${ }^{34}$ İ.S.: Ghasa (/Ghaza), Ghasije (/Ghaswe), Ghazidschah.

${ }^{35}$ İ.S.: Gedekli Kiatibi, Gedekli Schagird, Gedekli Saim, Gedekli Muteterriker, Gedekli Tschausch.

${ }^{36}$ İ.S.: Aga Khan, Chakani, Chanat (/Chanlik/Khanat), Chanum (/Chanym/Hanum), Defterchan, Tabul Khan.

${ }^{37}$ Hâkim ve Hekim sözcükleri, Herder (3/207) ve Pierer (7/861) sözlüklerinde aynı madde içinde her iki anlamı da verilerek açıklanmıştır.

38 İ.S.: Al-Hakim, Hakim (/Hekim) Baschi, Hakim Effendi.
} 
34. Halife $>$ Chalif $/ \mathrm{K}(\mathrm{h})$ alif $^{39}$

Brockhaus (Chalif/Kalif) (1/919), Herder (Khalif) (3/584-585). Wissen F. (Kalif), Wissen W. (Kalif).

35. Harem $>$ Harem $^{40}$

Duden (Harem), Karaağaç (Harem) (351), Keleş (Harem) (126), Meyer (Harem) (8/806), Pierer (Harem) (8/34-35) Wissen F. (Harem), Wissen W. (Harem).

36. Haremeyn $^{41}>$ Aremein $^{42}$

Pierer (Aremein) (1/679).

37. Haseki > Aseki / Assaky / (Kh)Asseky / Chasseki ${ }^{43}$

Herder (Chasseki) (2/68-69), Meyer (Chasseki) (3/896), Pierer (Aseki/Assaky/(Kh)Asseky/Chasseki) (1/837)

38. Haznedar $>(\mathrm{C})$ Hasnadar / Haznadar ${ }^{44}$

Meyer ((C)Hasnadar/Haznadar) (3/896).

39. Hekim $^{45}>$ Hakim $^{46}$

Herder (Hakim) (3/207), Meyer (Hakim) (8/639), Pierer (Hakim) (7/861).

40. Hidiv > Chediv(e) / Chidiv / Khedive

Brockhaus (Chediv/Khedive) (1/960), Meyer (Chedive/Chidiv/Khedive) (3/907), Duden (Khedive), Keleş (Khedive) (127), Wissen F. (Khedive), Wissen W. (Khedive).

41. Hoca > (C)Hodscha / Hodgias (çoğul) / Hogia / Kodschea ${ }^{47}$

Duden (Hodscha), Karaağaç (Hodscha) (372), Keleş (Hodscha) (127), Meyer ((C)Hodscha) (3/907), Pierer ((C)Hodscha/Hodgias/Hogia/Kodschea) (4/67), Wissen F. (Hodscha).

42. Humbarac1 $>$ Kumbaradschy ${ }^{48}$

Pierer (Kumbaradschy) (9/888).

43. Hünkâr ${ }^{49}>$ Hunkear / (C)Hunkjar / Hünkiar ${ }^{50}$

Meyer ((C)Hunkjar/Hünkiar) (9/658), Pierer (Hunkear) (8/626).

44. İbriktar $>$ Imbrikdar ${ }^{51}$

Pierer (Imbrikdar) (8/831).

${ }^{39}$ İ.S.: Chalifat (K(h)alifat/Kalifentum).

${ }^{40}$ I.S.: Haremsdame (/frau), Haremswächter.

${ }^{41}$ Sözcük Türkçede bir unvan olmasa da Almanca karşılığı hazine yöneticisi, sorumlusu anlamına gelen Schatzmeister sözcügüyle tanımlanmıştır.

42 İ.S.: Aremein-Muhasebedschi, Aramein-Mukataa, Chadim al Haramaim.

${ }^{43}$ I.S.: Aseki (/Assaky/Asseky/Chasseki/Chassakji)-Sultanin.

${ }^{44}$ İ.S.: Hasnadar (/Kasnadar)-Baschi, Hasnadar-Kadyn, Hasnadar Usta.

${ }^{45}$ Bkz. 36. dipnot.

${ }^{46}$ İ.S.: Hakim Baschi, Hakim Effendi.

${ }^{47}$ İ.S.: Chawadscha.

${ }^{48}$ İ.S.: Kambaradschi (/Kumbaradschy)-Baschi.

${ }^{49}$ Sözcük, Pierer sözlüğünde Hünkâr İmamı (sarayın birinci ve ikinci imamları) olarak açılanmıştır. Madde başı olarak bulunmamakla birlikte Hünkâr İskelesi maddesinin tanımlarında (8/626, 18/245) sözcügün Hunkiar ve Unkiar şekilleri de geçmektedir.

${ }^{50}$ İ.S.: Hunkear Imami, Hunkiar (/Hunkjar)-Esklessi (/-iskallesi/-(i)skelessi/-iskeliesi/-iskellesi/-skalessi) (/Unkiar-Eskelessi), Hunkiar-Tschairi

${ }^{51}$ İ.S.: Imbrikdar-Aga. 
45. İmam $>\operatorname{Imam}^{52}$

Meyer (Imam) (9/765-766), Pierer (Imam) (8/830).

46. $\operatorname{Kad}_{1}>$ Kadi / Kasi ${ }^{33}$

Herder (Kadi) (3/523), Karaağaç (Kadi) (412), Meyer (Kadi/Kasi) (10/414), Pierer (Kadi) $(9 / 210)$.

47. $\operatorname{Kad}^{54}>$ Kadine / Kadun / Kadyn / Khadunnah ${ }^{55}$

Karaağaç (Kadine) (412), Meyer (Kadyn) (10/416), Pierer (Kadun/Khadunnah) (9/211).

48. Kâhya > Kiaja / Kjaja ${ }^{56}$

Meyer (Kjaja): (11/83), Pierer (Kiaja): (9/466).

49. Kap1c1 > Capigi / Kapidschi / Kapudschi ${ }^{57}$

Brockhaus (Kapidschi/Kapudschi) (1/932), Herder (Kapidschi) (3/541), Meyer (Kapidschi/Kapudschi) (10/606), Pierer (Capigi/Kapidschi) (3/652).

50. Kâtip > K(i)atib(i) / Kjatib ${ }^{58}$

Meyer (Katib/Kiatib/Kjatib) (10/753), Pierer (Katib/Kiatibi) (9/381).

51. Kavas > Chawas / Chawaß / Kavaß / Kawass(e) / Kawaß / Kawwas / Khawas ${ }^{59}$

Brockhaus (Chawas/Kawaß/Kawwas) (1/983), Duden (Kawass(e)), Meyer (Kawaß) (10/795), Karaağaç (Kawass) (462), Keleş (Kawass(e)) (127), Pierer (Chawaß/Kavaß/Khawas) (9/402), Wissen F. (Kawass(e)), Wissen W. (Kawass(e)).

52. Kaymakam $>$ Kaimakam $^{60}$

Brockhaus (Kaimakam) (1/915), Meyer (Kaimakam) (10/430), Pierer (Kaimakam) (9/222).

53. Kilavuz $>$ Kulagus $^{61}$

Pierer (Kulagus) (9/884).

54. Kolcu > Koldschi

Pierer (Koldschi) (9/655).

55. Komitac1 > Komitadschi

Meyer (Komitadschi) (11/324-325), Wissen F. (Komitadschi).

56. Korucu $>$ Koridschis (çoğul)

Pierer (Koridschis) (9/722).

${ }^{52}$ İ.S.: Imam-Dschuma.

${ }^{53}$ İ.S.: Cadileskier (/Kadiasker/Kadileskier/Kasiasker/Kaziasker), Istambul (/Stambul) Kadiligi (/Kadisi), Kadi Naibi, Kadi Weliki, Kadilik, Kaditisk, Kaziaskerlik.

${ }^{54}$ Sözcügün Kadin ve Khadune şekilleri, sözlüklerde madde başı olarak bulunmamakla birlikte bu sözcükten türeyen diğer sözcüklerin ya da Türklerle alakalı diğer maddelerin açıklamalarında geçmektedir.

${ }^{55}$ İ.S.: Basch-Kadun (/-Kadyn), Chasseki Kadin, Hamamdschi Kadin, Hasnadar-Kadyn, Kehaja (/Kjaja/Kietchuda) Kadine (/Kadun) (Kadun-Kietchuda/Kiaja).

${ }^{56}$ İ.S.: Basch-Kapu Kiaja, Hasne-Kjajasi, Kapidschilar Kiajassi, Kapu-Kjaja, Kehaja (/Kjaja/Kietchuda) Kadine (/Kadun) (Kadun-Kietchuda/-Kiaja), Kiaja Kiatibi, Kiaja (/Kjaja)-Beg, Kjetchuda-Bey, Kul-Kjetchuda.

${ }^{57}$ İ.S.: Basch-Kapu Kiaja, Basch-Kapudschi (/Kapudschi-Baschi), Basch-Kapu Oglani, Capi (/Kapi)-Aga (/Kapu-Agassi), Kapi (/Kapu), Kapidschilar Kiajassi, Kapikuli (/Kapu Kuli), Kapu Agassi, Kapu Chalki, Kapu Jasidschi, Kapu Kiazalar.

${ }^{58}$ İ.S.: Basch-Kiatib, Gedekli Kiatibi, Katib Tschelebi, Kiaja Kiatibi, Liman Kiatibi, Mabeini Humajun Kiatibi, Mehkmeke Kiatibi, Sirr-K(j)atib(i).

${ }^{59}$ İ.S.: Kawass-Baschi.

${ }^{60}$ İ.S.: Kaimakam-Beg.

${ }^{61}$ İ.S.: Kulagus Tschausch. 
57. Kral $>$ Kral

Meyer (Kral) (11/563), Pierer (Kral) (9/761).

58. $\mathrm{Kul}>\mathrm{Kul}^{62}$

Pierer (Kul) (9/884).

59. Lağ $1 \mathrm{mc}$ > Laghundschi / Lagumschi / Lagundschiy ${ }^{63}$

Pierer (Laghundschi/Lagumschi/Lagundschiy) (10/24).

60. Lala $>\operatorname{Lal}(1) \mathrm{a}^{64}$

Meyer (Lala) (12/64), Pierer (Lal(l)a) (10/41).

61. Levent $>$ Levanti ${ }^{65}$

Pierer (Levanti) $(10 / 322)$.

62. Mektupçu $>$ Mektubdschi ${ }^{66}$

Meyer (Mektubdschi) (13/566).

63. Memluk > Mamelu(c)k / Mamelucken (çoğul)

Brockhaus (Mamelucken) (2/119), Keleş (Mamelucken) (128), Wissen F. (Mamelu(c)k).

64. Mihmandar $>$ Mihmandar ${ }^{67}$

Herder (Mihmandar) (4/183), Pierer (Mihmandar) (11/249).

65. Molla > Mala / Mewla / Molla / Mulla(h) ${ }^{68}$

Brockhaus (Mewla/Molla/Mullah) (2/201-202), Duden (Mulla(h)), Herder (Molla) (4/218), Karaağaç (Molla) (614), Keleş (Mulla(h)) (128), Meyer (Mala/Molla/Mulla) (14/39), Pierer (Molla/Mullah) (11/367), Wissen F. (Molla/Mulla(h)), Wissen W. (Molla/Mulla(h)).

66. Muhacir $>$ Muhadschir

Meyer (Muhadschir) (14/212).

67. Muhtar $>$ Muchtar

Brockhaus (Muchtar) (2/220), Duden (Muchtar), Keleş (Muchtar) (128), Meyer (Muchtar) (14/207), Wissen F. (Muchtar), Wissen W. (Muchtar).

68. Mutasarrif $>$ Mute(s)sarrif ${ }^{69}$

Brockhaus (Mutessarrif) (2/232) Meyer (Mutesarrif) (14/330).

69. Müdür $>$ Mudir $^{70}$

Duden (Mudir), Karaağaç (Mudir) (623), Keleş (Mudir) (128), Meyer (Mudir) (14/209),

Wissen F. (Mudir), Wissen W. (Mudir).

\footnotetext{
${ }^{62}$ İ.S.: Baki Kuli, Kapikuli, Kul-Kjetchuda, Kul-Kjöhaja, Seratkuly.

${ }^{63}$ İ.S.: Laghundschi-Baschi.

${ }^{64}$ İ.S.: Lalabaschi.

${ }^{65}$ İ.S.: Lewendtschiftlik Askeri.

${ }^{66}$ İ.S.: Mektubdschi Efendi.

${ }^{67}$ İ.S.: Mehmander (/Mihmandar)-Baschi.

${ }^{68}$ İ.S.: Kasi-Molla(h) (/-Mulla(h))

${ }^{69}$ İ.S.: Mute $(s)$ sarriflik.

${ }^{70}$ İ.S.: Mudirije, Müdirat.
} 
70. Müfettiş > Mufettisch

Brockhaus (Mufettisch) (2/221), Meyer (Mufettisch) (14/210).

71. Müftü ${ }^{71}>$ Mufti $^{72}$

Brockhaus (Mufti) (2/221), Herder (Mufti) (4/263), Meyer (Mufti) (14/211), Pierer (Mufti) (11/500), Karaağaç (Mufti).

72. Mühürdar $>$ Mühürdar ${ }^{73}$

Meyer (Mühürdar) (14/221).

73. Mülazım $>$ Mulasim $^{74}$

Meyer (Mulasim) (14/222).

74. Müsellem ${ }^{75}>$ Musselim

Pierer (Musselim) (11/589).

75. Müslüman ${ }^{76}>\operatorname{Muselman}(\mathrm{n})^{77}$

Duden (Muselman(n)), Keleş (Muselman) (128), Karaağaç (Muselman) (628), Wissen W. $(\operatorname{Muselman}(n))$

76. Müstahf $1 z^{78}>$ Mustahafiz / Mustahfis

Brockhaus (Mustahafiz) (2/232), Meyer (Mustahfis) (14/326).

77. Müsteşar $>$ Musteschar ${ }^{79}$

Brockhaus (Musteschar) (2/232), Meyer (Musteschar) (14/329).

78. Müşir $>$ Muschir(r) / Müschir ${ }^{80}$

Brockhaus (Muschir) (2/230), Duden (Muschir/Müschir), Keleş (Muschirr/Müschir) (128), Meyer (Muschir) (14/297), Pierer (Muschir) (19/873), Wissen W. (Muschir).

79. Mütevelli > Mutewelli

Meyer (Mutewelli) (14/330-331).

80. Naip $>$ Naib $^{81}$

Herder (Naib) (4/286), Meyer (Naib) (14/398), Pierer (Naib) (11/655).

\footnotetext{
${ }^{71}$ Herder dışındaki Almanca sözlüklerde Arapça asıllı olarak verilen sözcügün Türk kültüründeki yerine değinilmemiştir, ancak tanımların devamında müftülerin başı olarak verilen şeyhülislam sözcüğü Türklerdeki şekliyle açıllanmıştır. Herder sözlüğünde ise müftü sözcüğü doğrudan şeyhülislam olarak tanımlanmıştır.

72 İ.S.: Groß-Mufti.

${ }^{73}$ İ.S.: Mühürdar Efendi.

${ }^{74}$ İ.S.: Mulasim Ewwel, Mulasim Sani.

${ }^{75}$ Almanca sözlüklerde duba köprü yapıcısı olarak tanımlanan sözcüğün bu anlamı Tarih Terimleri Sözlüğü’ndeki (1974) müsellem maddesinde geçmektedir.

${ }^{76}$ Sözcük Brockhaus, Herder, Meyer ve Pierer sözlüklerinde ya Arapça asıllı olarak tanımlanmış ya da köken bilgisi verilmemiştir.

77 İ.S.: Islam(isch), Islamisation, Islamisieren, Islamisierung, Islamismus, Islamist(in), Islamistisch, Islamit(in), Islamitisch, Muselmanin, Muselmännin, Moslim(in), Muslim(in).

${ }^{78}$ Güncel Türkçe Sözlük’te bulunmayan sözcüğün Türkçe şekli Tarih Terimleri Sözlüğündeki (1974) müstahfiz maddesinden alınmıştır.

${ }^{79}$ İ.S.: Char(i)dschie Musteschari.

${ }^{80}$ İ.S.: Muschirat.

${ }^{81}$ İ.S.: Ayak Naib.
} 
81. Nazir > Nasir / Nazir ${ }^{82}$

Brockhaus (Nasir/Nazir) (2/244), Meyer (Nasir/Nazir) (14/434), Pierer (Nasir/Nazir) (11/688).

82. Nefer $>$ Nefer

Pierer (Nefer) (11/767).

83. Odalık > Odaliske / Odalisken (çoğul)

Brockhaus (Odaliske) (2/299), Duden (Odaliske), Herder (Odaliske) (4/376), Karaağaç (Odaliske) (648), Keleş (Odaliske) (128), Meyer (Odaliske) (14/897), Pierer (Odalisken) (12/208), Wissen F. (Odaliske), Wissen W. (Odaliske).

84. Oğlan ${ }^{83} \&$ Oğlu (< Oğul) > Oglan / Ulan / Uhlena \& Oglu ${ }^{84}$

Duden (Ulan), Herder (Oglan\&Oglu) (4/393, 393), Karaağaç (Ulan/Uhlena) (649), Keleş (Ulan) (129), Pierer (Oglan\&Oglu) $(12 / 233,233)$, Wissen F. (Ulan), Wissen W. (Ulan).

85. Osmanll ${ }^{85}>$ Osmane / Osmanen (çoğul) / Osmanli / Ottoman(e) ${ }^{86}$

Brockhaus (Osmanen/Osmanli) (2/322-323), Duden (Osmane/Ottomane), Keleş (Ottoman) (128), Meyer (Osmanen/Osmanli) (15/161), Wissen F. (Osmane/Ottomane), Wissen W. (Osmane).

86. Oturak ${ }^{87}>$ Ottoraken (çoğul) / Oturaks (çoğul)

Pierer (Ottoraken/Oturaks) (12/523).

87. Padişah > Padischah

Brockhaus (Padischah) (2/338), Herder (Padischah) (4/440), Karaağaç (Padischah) (668), Meyer (Padischah) (15/302), Pierer (Padischah) (12/554).

88. Paşa > Bassa / Pascha / Wassa ${ }^{88}$

Brockhaus (Bassa/Pascha) (2/360), Duden (Bassa/Pascha), Herder (Pascha) (4/468), Karaağaç (Pascha) (678), Keleş (Bassa/Wassa/Pascha) (126, 128), Meyer (Bassa/Pascha) (15/475), Pierer (Bassa/Pascha) (12/722), Wissen F. (Pascha), Wissen W. (Bassa/Pascha).

89. Peyk $^{89}>$ Peik

Herder (Peik) (4/482), Pierer (Peik) (12/782).

90. Piyade $>$ Piade

Pierer (Piade) (13/113).

\footnotetext{
82 İ.S.: Adlije Nasiri, Bahrije Nasiri, Chardschie (/Charidschije/Charadschie/Kharidschijie) Nasiri, Dachilije Nasiri, Devlet-Naziri, Evkaf-Nasiri, Gömrük (/Rusumat) Nasiri, Hanbar Nasiri, Liman Nasiri, Malie (/Malije) Nasiri, Sabtije Nasiri, Terssane Nasiri, Tidjaret (/Tidscharet) Nasiri, Tuna Kalaalar in Nasiri.

${ }^{83}$ Almanca sözlüklerde sözcüğ̈nün Oglan şekli okul anlamında bulunurken Ulan/Uhlena şekli atlı asker anlamında açıklanmıştır.

${ }^{84}$ I.S.: Adschem(i) Oglan (/Azem-Oglam/Azutsch-Oglam), Ibrik Oglani, Ichoglans (/Idschoglans), Ikinzi Kapa Oglani, Ulanka, Spahi-Oglan \& Hadschi Oglu Bazardschick, Kulugli (/Kul-oglu), Oglu-Balaklar, Paßvan-Oglu.

${ }^{85}$ Sözcük, Pierer (12/397) sözlüğünde Osmanen ve Osmanli şekliyle Osman maddesinde açıllanmıştır.

${ }^{86}$ İ.S.: Osman, Osmanentum, Osmanin, osmanisch, Ottoman, Ottomanin.

${ }^{87}$ Almanca sözlüklerde emekliye ayrılmış yeniçeri anlamında kullanılan sözcüğün bu anlamı Tarih Terimleri Sözlüğ̈̈’ndeki (1974) oturak maddesinde bulunmaktadır.

${ }^{88}$ İ.S.: Barbar Pascha, Defterdar-Pascha, Derbenti-Pascha, Ferik Pascha, Javan (/Javer/Jawer)-Pascha, Kapitan (/Kaptan/Kapudan)-Pascha, Karakdschi Pascha, Liwa-Pascha, Nischandschi Pascha, Paschalik, Seimen Pascha.

${ }^{89}$ Almanca sözlüklerde $u l a k$, haberci anlamında kullanılan sözcüğün bu anlamı Türk Dil Kurumu sözlüklerinde bulunmayıp İslam Ansiklopedisi’nin (Ertuğ, 2007, s. 263-264) Peyk (Osmanlılar) maddesinde geçmektedir.
} 
91. Reaya > Raja(h) / Rajas (çoğul)

Brockhaus (Rajah) (2/488), Duden (Rajah), Herder (Rajah) (4/662), Karaağaç (Rajah) (704), Keleş (Rajah) (128), Meyer (Raja(h)) (16/578-579), Pierer (Rajas) (13/803), Wissen F. (Rajah).

92. Reis $^{90}>$ Reis $^{91}$

Herder (Reis) (4/697), Meyer (Reis) (16/764-765), Pierer (Reis) (14/16).

93. Sadrazam ${ }^{92}>$ Sadrasam / Sadrazam ${ }^{93}$

Meyer (Sadrasam/Sadrazam) (17/410).

94. Saka > Saka

Meyer (Saka) (17/456).

95. Sancaktar ${ }^{94}>$ Sandschaktar ${ }^{95}$

Brockhaus (Sandschaktar) (2/604).

96. Sekban ${ }^{96}>$ Seghban / Seymen

Pierer (Seghban/Seymen) $(15 / 769,827)$.

97. Selçuklu > Seldschuke / Seldschuk(id)en (çoğul) ${ }^{97}$

Brockhaus (Seldchuken) (2/686), Duden (Seldschuke), Herder (Seldschuken) (5/179), Meyer (Seldschuk(id)en) (18/319-320), Pierer (Seldschuken) (15/810), Wissen (Seldschuke).

98. Serasker $>$ Seraskier ${ }^{98}$

Brockhaus (Seraskier) (2/692), Herder (Seraskier) (5/189), Karaağaç (Seraskier) (745), Meyer (Seraskier) (18/354), Pierer (Seraskier) (15/863).

99. Serdar $>$ Sardar / Serdar / Sirdar ${ }^{99}$

Brockhaus (Serdar/Sirdar) (2/693), Meyer (Serdar/Sirdar) (18/368), Pierer (Sardar/Serdar) $(15 / 883)$.

100. Silahtar $>$ Silihdar / Silahdari ${ }^{100}$

Pierer (Silihdar/Silahdari) (16/103).

\footnotetext{
${ }^{90}$ Sözcük, Brockhaus (2/512) sözlüğünde madde başı olarak sadece Reis Efendi şeklinde bulunmaktadır.

${ }^{91}$ İ.S.: Akhiam-Adliie-Reissi, Liman Reissi, Reis-Ef(f)endi, Reis-i-Beledije, Reis-i-Machkeme (/Machkeme Reissi), Reis-i-Schura-i-Dewlet (/Schura-i-Dewlet Reissi).

92 Sözcük, Meyer (8/428) sözlüğünün Großwesir maddesinde veziriazam sözcüğüyle eşanlamlı olarak gösterilmiştir. Sözcüğün Sadr-Aasam ve Sadr-iAsam şekilleri, yine aynı sözlüğün Großwesir (8/428) ve Sadr (17/410) maddelerinde geçmektedir.

${ }_{93}$ İ.S.: Sadaret, Sadaret-i-Usma, Sadr, Sadr-Aasam, Sadr-i-Asam, Sadrein Muchteremein, Sudur.

${ }^{94}$ Sözcük için Brockhaus sözlügünde Alemdar maddesine göndermede bulunulmuştur. Ayrıca sözcügün Sandschakdar şekli madde başı olarak bulunmamakla birlikte Meyer (17/544) sözlüğünde Sandschak maddesinde açılanmıştır.

${ }^{95}$ İ.S.: Sandschak, Sandschak-Beg, Sandschak-Scherif, Sandschakat

96 Sözcük, Pierer sözlüğünde asıl olarak Seghban şeklinde bulunmaktadır. Bununla birlikte Seymen şekli de yeniçerilerin ana bölümü olarak tanımlanmıştır. Sözcüğün Seymen şekli, Türkçedeki seğmen sözcügüyle benzerlik gösterse de bu sözcük aynı sözlükte Saimeni (14/761) olarak omuzlarında kaplan ya da pars derisi taşıyan atlı okçu tanımıyla verilmiştir. Dolayısıyla Seymen sözcügüyle kastedilen Seghban sözcügü olmalıdır.

${ }^{97}$ İ.S.: Seldschukin.

${ }^{98}$ İ.S.: Seraskier-Kapussi, Seraskierat.

${ }^{99}$ İ.S.: Serdar-Ekrem.

100 İ.S.: Budschukdschi Silihdar, Silihdar-Aga(lar)
} 
101. Sipahi $>$ S(i)pahi / S(i)pahis (çoğul $)^{101}$

Brockhaus (S(i)pahis) (2/730), Duden (Spahi), Herder (Spahis) (5/260), Karaağaç (Spahi) (761), Keleş (Spahi) (129), Meyer (S(i)pahi) (18/645), Pierer (Spahis) (16/325), Wissen F. (Spahi), Wissen W. (Spahi)

102. Softa $>$ Softa / Softas (çoğul) / Suachte

Duden (Softa), Herder (Softas) (5/240), Keleş (Softa) (129), Meyer (Softa) (18/568), Pierer (Softa/Suachte) (16/243).

103. Solak > Solaks $(\text { çoğul })^{102}$

Herder (Solaks), Pierer (Solaks) (16/252).

104. Sultan $>$ Sultan ${ }^{103}$

Brockhaus (Sultan) (2/789), Herder (Sultan) (5/377), Karağaç (Sultan) (771), Keleş (Sultan) (129), Meyer (Sultan) (19/198), Pierer (Sultan) (17/81).

105. Süvari $>$ Suwari

Pierer (Suwari) (17/116).

106. Şeyhülislam ${ }^{104}>$ Scheich al-Islam / Scheich ul-Islam ${ }^{105}$

Karaağaç (Scheich al-Islam) (792), Meyer (Scheich ul-Islam) (17/723).

107. Tercüman > Dragoman / Terdschuman / Truchemann / Trugman / Trüschmang ${ }^{106}$

Herder (Dragoman) (2/441), Meyer (Dragoman/Terdschuman) (5/159), Pierer (Drogoman/Truchemann/Trugman/Trüschmang) (5/288).

108. Teşrifatçı $>$ Teschrifadschi

Pierer (Teschrifadschi) (17/396).

109. Timarlı > Timarioten (çoğul) / Timarlery ${ }^{107}$

Pierer (Timarioten/Timarlery) (17/601).

110. Topçu $>$ Top(i)dschi / Top(t)schi ${ }^{108}$

Herder (Toptschi) (5/498), Pierer (Top(i)dschi/Topschi) (17/684).

111. Toprakl1 ${ }^{109}>$ Toprali

Pierer (Toprali) (17/689).

112. Turnacı $>$ Tumandschis (çoğul) $)^{110}$

Pierer (Tumandschis) (17/927).

\footnotetext{
${ }^{101}$ İ.S.: Sipahi-Agalar, Spahi-Oglan

102 İ.S.: Solakbaschi.

103 İ.S.: Aseki (/Assaky/Asseky/Chasseki/Chassakji)-Sultanin, Favorit-Sultanin (Favorite-Sultanin/Sultanin Favorite), Großsultan, Sultan-Valide (Großsultanin/Sultan-Valideh/Sultana-Walide/Sultanin-Mutter/Sultanin Valide/Sultanin Walide/Valideh-Sultan/Walide Sultan/Walide Sultanin), Sultana, Sultanat, Sultanin, Sultanine.

${ }^{104}$ Sözcük, Brockhaus (2/221), Herder (4/263) ve Pierer (11/500) sözlüklerinde Scheich (/Scheikh) ul-Islam şekliyle Müfti maddesinde, ayrıca Brockhaus (2/624) sözlüğünde Scheich maddesinde ve Pierer (15/120) sözlügünde Scheik(h) maddesinde açılanmıştır.

${ }^{105}$ İ.S.: Scheichulislamat.

${ }^{106}$ İ.S.: Basch-Terdschuman, Terdschuman-i Diwan-i Humajun

${ }^{107}$ İ.S.: Timar (-Spahis), Timarli.

${ }^{108}$ İ.S.: Top(d)schidere, Topdschi (/Toptschi) Baschi, Topdschilar Agha, Toptschilar-Aga

${ }^{109}$ Sözcük için Pierer sözlüğünde Timarlı (sipahiler) maddesine göndermede bulunulmuştur.

${ }^{110}$ İ.S.: Tournadschy-Baschy.
} 
113. Tüfekçi > Tufenktschis (çoğul) / Tuffendschis (çoğul) ${ }^{111}$

Pierer (Tufenktschis/Tuffendschis) (17/922).

114. Ulak > Lakai / Ulacid / Ulak

Herder (Ulak) (5/547), Karaağaç (Lakai) (874), Pierer (Ulacid) (18/136), Wissen F. (Lakai).

115. Ulema $>$ Ulema $^{112}$

Brockhaus (Ulema) (2/885), Herder (Ulema) (5/547), Karaağaç (Ulema) (875), Keleş (Ulema) (129), Meyer (Ulema) (19/878), Pierer (Ulema) (18/137).

116. Usta $>$ Usta $^{113}$

Meyer (Usta) (19/978).

117. Vali ${ }^{114}>$ Vali / Wali / Weli ${ }^{115}$

Brockhaus (Vali/Wali) (2/946), Duden (Wali/Weli), Karaağaç (Wali) (885), Keleş (Wali/Weli) (129), Meyer (Vali/Wali/Weli) (20/343), Pierer (Wali) (18/809).

118. Valide ${ }^{116}>$ Walide ${ }^{117}$

Duden (Walide), Meyer (Walide) (20/343).

119. Vekil $>$ Wekil $^{118}$

Duden (Wekil), Keleş (Wekil) (129), Meyer (Wekil) (20/507).

120. Vezir ${ }^{119}>$ Vezi(e)r / Vesir / Visir / Vizir / Wes(s)ir / Wezir ${ }^{120}$

Brockhaus (Vezier/Wesir) (2/973-974), Duden (Vezier/Wesir), Herder (Vezier/Wesir) (5/619), Karaağaç (Wesir) (891), Keleş (Wesir) (129), Meyer (Vezier/Vezir/Vizir/Wesir) (20/551), Pierer (Vesir/Vezier/Visir/Wes(s)ir/Wezir) (18/548), Wissen F. (Vezier/Wesir).

121. Yaver $>$ Jawer $^{121}$

Meyer (Jawer) (10/214).

122. Yazıc1 > Dschasitschi

Pierer (Dschasitschi) (5/361).

123. Yeniçeri > Janitschar / Janitscharen (çoğul) / Jenitschjeri / Jenkridschari ${ }^{122}$

Brockhaus (Janitscharen) (1/890), Duden (Janitschar), Herder (Janitscharen) (3/468-469), Keleş (Janitschar) (127), Meyer (Janitscharen) (10/168), $\quad$ Pierer (Janitscharen/Jenitschjeri/Jenkridschari) (8/737-738), Wissen F. (Janitschar), Wissen W. (Janitschar).

\footnotetext{
${ }^{111}$ İ.S.: Tuffendschi-Baschi.

112 İ.S.: Alim.

113 İ.S.: Hasnadar Usta.

${ }^{114}$ Sözcüğün Meyer (20/510) sözlüğündeki Weli şekli sadece Arap-İslam kültüründeki anlamıyla açılanmıştır. Wissen F. (Wilajet maddesi) sözlüğünde ise vilayet maddesinde Türkçe-Arapça olarak verilmiştir.

${ }^{115}$ İ.S.: Vilajet, Wilajet.

${ }^{116}$ Sözcük, Brockhaus (2/789) sözlüğünde Balideh (/Valideh) şekliyle Sultan maddesinde, Herder (5/377) sözlüğünde Sultan-Valide şekliyle Sultan maddesinde ve Pierer (17/81-82) sözlüğünde Sultanin Valide ve Walide Sultanin şekilleriyle Sultanin maddesinde açıklanmıştır.

117 İ.S.: Balideh, Sultan-Valide (/Sultana-Walide/Sultan-Valideh/Sultanin Valide/Sultanin Walide/Valideh-Sultan/Walide Sultan/Walide Sultanin), Valide, Valideh.

${ }^{118}$ İ.S.: Basch-Wekil, Meclis-i Wukela, Vekil (/Wekil) Scheres, Wukela.

${ }^{119}$ Sözcük, Duden (Wesir maddesi) sözlüğünde veziriazam (Großwesir) olarak tanımlanmıştır.

${ }^{120}$ İ.S.: Großwesir (/Großvezier), Vezier (/Wesir)-Azem, Wesir-i Asam, (Groß)Wesirat.

${ }^{121}$ İ.S.: Javan (/Javer/Jawer)-Pascha.

122 İ.S.: Janitscharen-Aga (/Jenitscheri-Agassi), Janitscharen-Effendi, Janitscharencap, Janitscharenmusik, Tscheri.
} 
124. Yürük ${ }^{123}>$ Dschuregsians (çoğul) / Dschuruken (çoğul) / Juruken (çoğul)

Pierer (Dschuregsians/Dschuruken/Juruken) (5/366).

125. Zağarcı $>$ Zagrandschis (çoğul)

Pierer (Zagrandschis) (19/486).

126. Madde Başı Olmayanlar ${ }^{124}$

Aşçı > Akhgi: Janitscharen maddesi (Pierer, 8/737-738).

Derbentçi > Derbendschi: Derbend maddesi (Meyer, 4/652).

Samsuncu > Samsondschis (çoğul): Janitscharen maddesi (Pierer, 8/737-738).

\section{Diğerleri ${ }^{125}$}

Acantses / Acanzis: Türk İmparatorluğu'nda hafif birliklerdeki gönüllüler ${ }^{126}$

Agiades: (Türkçe) Hendekçi askerler ${ }^{127}$

Astandes: (Türkçe) Angaros ${ }^{128}$

Musselin: (Türkçe) Bir paşanın emir subay1 ${ }^{129}$

Muzzi: (Türkçe) Gemilerde çalışmak zorunda olan köleler ${ }^{130}$

Sebezi: (Türkçe) Bir tür ağır atll ${ }^{131}$

Serökdschi: (Türkçe) Oda hizmetçisi ${ }^{132}$

Utsch Raschi: (Türkçe 20 adamın kumandanı) Çavuş ${ }^{133}$

\section{Değerlendirme ve Sonuç}

Yapılan taramalar sonucunda Alman dilinde Türk devlet sistemine ait $135+1^{134}$ unvan belirlenmiştir. Madde başı olan unvanlardan türeyen birleşik unvanlar da (ilintili sözcükler)

${ }^{123}$ Sözcük için Pierer sözlüğünde Tımarlı (sipahiler) maddesine göndermede bulunulmuștur. Ayrıca Meyer sözlüğünün Jürük (10/391) maddesinde bir tür Türk topluluğu olan Yörükler açıklanmıştır.

${ }^{124} \mathrm{Bu}$ başlıkta, madde bașı olmayıp başka maddelerde geçen unvanlar listelenmiștir. Baş sözcüğüyle birleșik ad olușturmuș unvanların yalın şekilleri bu başlıkta verilmemiştir. Örneğin, Nischandschi unvanı, Meyer (14/709-710) sözlüğünde Nischan maddesinde açıklanmasına rağmen, unvanın Nischandschi Baschi șekli baş maddesinin İ.S.sinde verildiği için buraya alınmamıștır (Bkz. 12. dipnot).

${ }^{125}$ Bu bașlıkta, Türkçe olduğu ya da Türkçeden geçtiği tespit edilen, ancak Türkçede hangi sözcükten alındığını belirlenemeyen sekiz unvan Almancadaki anlamlarıyla birlikte listelenmiştir.

${ }^{126}$ Pierer sözlüğünde (1/67) tanımlanan sözcüğün hangi Türkçe sözcükten alındığı belirlenememiştir. Sözcük Türkçedeki akıncı unvanını çağrıştırsa da bu unvanın aynı sözlükte (1/244) akindschis maddesinde açıklanmış olması bu ihtimali azaltmaktadır.

${ }^{127}$ Pierer sözlügünde (1/184) tanımlanan sözcüğün hangi Türkçe sözcükten alındığı belirlenememiştir. Sözcükteki $a$ ve $g$ sesleri ile sözcügün hendekçi anlamından dolayı Türkçedeki lă̆ımcı unvanıyla ilişkisi olabilir.

${ }^{128}$ Pierer sözlüğünde (1/848) Türkçe olarak verilen bu sözcük Türkçe sözlüklerde bulunamamıştır. Ancak bazı eserlerde sözcüğün unvan olduğu görülmektedir. Örneğin Landering (2009, s. 50) bu unvandan şöyle söz eder: III. Artarkserkses, bunun üzerine Dareios'u, Yunanların astandes 'ulak' olarak yorumladıkları kraliyet unvanıyla onurlandırdı. Muhtemelen bu unvan, Artaşata'nın kraliyet haberleşmeleri ya da kraliyet yollarının bakım ve korumasından sorumlu olduğu anlamına geliyordu... Şahin (2014, s. 24) ise gezi metinlerindeki kayıtlara göre bu unvanın aslında Perslerde görüldüğü ve daha sonra Yunan ve Roma kültürüne geçtiği belirtilmiştir: Bu kayıtlarda yolda olan, mesaj ileten, mal ya da para taşıyan [...] çok sayıda insan hakkında bilgi verilmektedir. Posta yöneticisi (astandes), tez ulak, hızlı kosucular, atlı kosucular, atlı postacılar (angareion), çağrı postası [...] gibi bir dizi iş ve buna ifade eden kavramlar ortaya çıkmıştır. Pierer'in tanımda verdiği angaros sözcüğu ise Eski Yunanca kökenli Latince bir unvandır. Şahin'in belirttiği angareion sözcügüüle de ilişkilidir. Bu sözcük Perslerde atlı postacı, kraliyetin atlı postacısı ya da İran kralının postacısı şeklinde tanımlanır. Türkçedeki angarya sözcüğü de www.etimolojiturkce.com sitesindeki angarya maddesinin köken bilgisine göre bu sözcükten gelir ve İran'la ilișkisi vardır. Bu durumda astandes sözcügünün Perslerde bir tür ulak anlamına geldiği kesinlik kazanır. Ancak unvanın Türkçede kullanıldığına dair bir kaynak bulunamamıștır.

${ }^{129}$ Pierer sözlüğünde (11/589) tanımlanan sözcüğün hangi Türkçe sözcükten alındığı belirlenememiştir.

${ }^{130}$ Pierer sözlügünde (11/601) tanımlanan sözcüğün hangi Türkçe sözcükten alındığı belirlenememiștir.

${ }^{131}$ Pierer sözlüğünde (15/720) tanımlanan sözcüğün hangi Türkçe sözcükten alındığı belirlenememiştir. Sözcük Türkçedeki cebeci unvanını çağrıştırsa da cebecilerin bir yaya sınıfı olması bu ihtimali azaltmaktadır.

${ }^{132}$ Pierer sözlüğünde (15/891) tanımlanan sözcüğün hangi Türkçe sözcükten alındığı belirlenememiştir. Sözcükteki 's', 'r' ve 'k' sesleri ile '-dschi' (-cı) ekinden dolayı Türkçedeki sarıkçı unvanıyla ilişkisi olabilir.

${ }^{133}$ Pierer sözlüğünde (18/324) tanımlanan sözcüğün hangi Türkçe sözcükten alındığı belirlenememiștir. İlk sözcüğün $u c ̧$ olarak okunmasından dolayı sözcüğün, Türkçedeki $u c ̧$ sözcüğünü içeren bir unvanla ilişkisi olabilir.

${ }^{134}$ Madde Başı Olmayanlar başlığı ile Diğerleri başlığındaki unvanlar bu sayıya doğrudan dâhil edilmiştir. Baş (Basch-/-baschi) sözcügü tek başına unvan olmadığı için ‘+1' değeriyle gösterilmiştir. 
eklendiğinde bu sayı yükselmektedir. Tespit edilen unvanları belirli başlıklar altında değerlendirmek gerekirse:

1. Alana Göre: Bu başlık altında unvanlar; idare, ordu ve diğerleri (mesleki vb.) olmak üzere üç gruba ayrilır. Buna göre, tespit edilen unvanlardan padişah, sultan, vezir, vali, müftü, muhtar gibi unvanlar idareyle; yeniçeri, çavuş, sipahi, süvari, serdar, deli gibi unvanlar orduyla; hekim, dilmaç, tercüman gibi unvanlar meslek vb. ile ilgilidir. Bununla birlikte bazı unvanlar iki alanda da kullanılıyor olabilir. Örneğin paşa unvanı hem idarede hem orduda kullanılır ya da efendi unvanı hekim efendi olarak bir meslek unvanı, paşa efendi olarak bir devlet unvanı olur. Alana göre unvanlar arasında idari ve askerî unvanlar sayıca öne çıkmaktadır.

2. Cinsiyete Göre: Bu başlık altında unvanlar; erkek, kadın ve iki cinsiyete ait olmak üzere üç gruba ayrilır. Buna göre, tespit edilen unvanlardan harem, kadın, odalık, valide gibi unvanlar kadın; kadı, müşir, paşa, sancaktar, vezir gibi unvanlar erkek; Osmanl, sultan gibi unvanlar iki cinsiyete de aittir. Cinsiyete göre unvanlar arasında erkek cinsiyetindeki unvanlar sayıca öne çıkmaktadır.

3. Niceliğe Göre: Bu başlık altında unvanlar; tekil, çoğul ve topluluk adı olmak üzere üç gruba ayrilır. Buna göre tespit edilen unvanlardan harem, kadın, müdür, paşa, vekil gibi unvanlar tekil; asker, oturak gibi unvanlar -Türkçede tekilken Almancada- çoğul ve reaya gibi unvanlar topluluk adıdır. Niceliğe göre unvanlar arasında tekil unvanlar sayıca öne çıkmaktadır.

4. Sözcük Kökenine Göre ${ }^{135}$ : Bu başlık altında unvanlar; Türkçe, Doğu dilleri kökenli (Arapça, Farsça) ve Batı dilleri kökenli (Sırpça, Yunanca) olmak üzere üç gruba ayrılır. Buna göre, tespit edilen unvanlardan ă̆a, bey, kadın, paşa, yeniçeri gibi unvanlar Türkçe; asker, hidiv, kâtip, lala, müşir, vezir gibi unvanlar Doğu dilleri kökenli; kral, efendi gibi unvanlar Batı dilleri kökenlidir. Ayrıca, ayrı dillerden gelen kök ve ek birleşiminden oluşmuş türeme unvanlar da vardır. Örneğin, Arapça kökenli alem sözcüğü ile Farsça kökenli -dar eki birleşerek alemdar unvanını ya da Sırpça kökenli komita sözcüğü ile Türkçe kökenli -cı eki birleşerek komitacı unvanını oluşturmuştur. Sözcük kökenine göre unvanlar arasında, Osmanlı Türkçesi üzerindeki Arapça-Farsça etkisinden dolayı Doğu dilleri kökenli unvanlar sayıca öne çıkmaktadır.

5. Sözlük Türlerine Göre: Bu başlık altında unvanlar; 18. yüzyıl ortası ile 19. yüzyllın başı aralığında yazılmış olan Almanca ansiklopedik sözlüklerde bulunanlar, güncel Almanca sözlüklerde bulunanlar ve Türkçe çalışmalarda bulunanlar olmak üzere üç gruba ayrilır. Buna göre tespit edilen unvanlardan azap, dayı, kapıcl, silahtar, topçu, yürük gibi unvanlar Almanca ansiklopedik sözlüklerde; ağa, çavuş, dilmaç, kavas, molla, valide gibi unvanlar güncel Almanca sözlüklerde; bey, harem, kadı, kadın, padişah, ulak gibi unvanlar Türkçe çalışmalarda bulunmaktadır. Tespit edilen unvanlar birden fazla gruba ait olabilir. Sözlük türlerine göre unvanlar arasında, neredeyse bütün unvanları barındırdıkları için ansiklopedik sözlükler sayıca öne çımaktadır.

Yukarıdaki değerlendirmelere göre, Alman dilindeki Türk devlet sistemi unvanları arasında idari ve askerî alanda kullanılan unvanlar çoğunluğu oluşturmaktadır. Bu iki alan dışındaki unvanların sayısı, toplam sayı içinde birkaçı geçmeyecek kadar azdır. Bu nedenle unvanların

${ }^{135}$ Unvanların kökeni için Türk Dil Kurumunun Kişi Adları Sözlüğü de kullanılmıştır. 
Almancaya geçişinin; en yoğun olarak, Osmanlı/Türkiye ve Prusya/Almanya ilişkileriyle paralel gittiği, iki ulusun devletleri arasında yapılan anlaşmaların yanı sıra Türkiye'de görev yapan Alman askerî görevlilerin yazdığı mektup ve rapor gibi belgeler ile anı kitapları aracılığılyla sağlandığı söylenebilir. Özellikle askerî alanda kullanılan unvanların çokluğu, iki ülke arasında gerçekleşen yoğun askerî ilişkilerin doğal bir sonucudur. Diğer yandan, eski ansiklopedik sözlüklerde unvanların neredeyse tamamının (134) yer alması ve günümüz Almanca sözlükler (35) ile Türkçe çalışmalarda (37) sayıca daha az unvan bulunması, Almanya'yla yoğunlaşan siyasi-askerî ilişkiler sonucunda Almanca sözlüklere giren çoğu unvanın, Osmanlı Devleti’nin yıkılmasının ve Türkiye Cumhuriyeti'nin kurulmasının ardından kullanımdan kalkmasıyla açıklanabilir. ${ }^{136}$ Dolayısıyla sözlüklerde giderek azalan unvanlardan geriye sadece en çok bilinen ya da hâlâ kullanımda olan unvanlar kalmıştır.

$\mathrm{Bu}$ çalışmada, Türk ve Alman devletlerinin arasındaki idari-askerî ilişkiler sonucunda Almancaya geçen Türk devlet sistemi unvanları incelenmiştir. Ancak dillerin yaptığı sözcük alşverişi; siyaset, toplum, kültür ve sanat gibi birçok alanda gerçekleşmektedir. Türklerin de çeşitli uluslarla çeşitli alanlardaki ilişkileri Türkçenin sözcük alışverişini kayda değer biçimde etkilemiştir. Dolayısıyla verintilerle ilgili çalışmaların, söz konusu alanlarda ve çeşitli dillerde ayrı ayrı yapılması, konuyla ilgili sözlük çalı̧maları ile araştırmalarına katkı sağlayacağı gibi Türkçenin dünya dilleri arasındaki yerinin belirlenmesine de yardımcı olacaktır.

\section{Kaynakça}

Albayrak, M. (1995). Osmanlı-Alman İlişkilerinin Gelişimi ve Bağdat Demiryolu’nun Yapımı, OTAM Ankara Üniversitesi Osmanlı Tarihi Araştırma ve Uygulama Merkezi Dergisi, 6, 1-38. Doi: 10.1501/OTAM_0000000236.

Alkan, M.N. (2015). Hayranlı, Dostluk ve Çıkar Üçgeninde Türk-Alman İlişkileri, SDÜ Fen Edebiyat Fakültesi Sosyal Bilimler Dergisi, 34, 35-48.

Beydilli, K. (1981). 1790 Osmanlı-Prusya İttifâkı, Meydana Gelişi-Tahlili-Tatbiki. Doçentlik Tezi. İstanbul: İstanbul Üniversitesi.

Brockhaus, F.A. (1911). Kleines Konversation-Lexikon (Cilt 1-2). Leipzig: F. A. Brockhaus. http://www.zeno.org/Brockhaus-1911 (Erişim: 05 Ekim 2018).

Çalık, R. (1996). Colmar Freiherr Von Der Goltz (Paşa) ve Bazı Görüşleri. Atatürk Araştırma Merkezi Dergisi, 36, 765-817.

Duden. (2018). Duden Online Wörterbuch. www.duden.de (Erişim: 05 Ekim 2018).

Ertuğ, Z. T. (2007). Peyk (Osmanlllar). İslam Ansiklopedisi (Cilt 34). İstanbul: Türkiye Diyanet Vakfi. 263-264.

Etimoloji Türkçe. Türkçe Etimolojik Kelime İncelemeleri. http://www.etimolojiturkce.com (Erişim: 07 Ekim 2018).

${ }^{136}$ Burada verilen unvanların sayısına baş sözcüğü de dâhil edilmiştir. 
Herder, B., Herder, R. (1854-1857). Konversations-Lexikon (Cilt 1-5). Freiburg im Breisgau: Herdersche. http://www.zeno.org/Herder-1854 (Erişim: 05 Ekim 2018).

Karaağaç, G. (2008). Türkçe Verintiler Sözlüğü. Ankara: Türk Dil Kurumu.

Keleş, N. (2003). Türk Dili ve Kültürünün Alman Dili ve Kültürüne Etkileri, Milli Folklor, 57, 119-130. Doi: 10.14222/Turkiyat412.

Kula, O.B. (1992). Alman Kültüründe Türk Imgesi 1. Ankara: Gündoğan.

Lendering, J. (2009). Büyük İskender. Burak Sengir (Çev.). İstanbul: Kitap.

Meyer, J. (1902-1908). Großes Konversations-Lexikon (Cilt 1-20). Leipzig \& Wien: Bibliographisches Institut. http://www.zeno.org/Meyers-1905 (Erişim: 05 Ekim 2018).

Mora, N. (2011). Tarihten Günümüze Alman Kolektif Belleğinde Türk İmgesi ve Medyada Yansıması. AÜ Sosyal Bilimler Enstitüsü Dergisi, 15(2), 21-33.

Ortaylı, İ. (1983). Osmanlı İmparatorluğu’nda Alman Nüfuzu. İstanbul: Kaynak.

Özgüldür, Y. (1993). Yüzbaşı Helmut von Moltke'den Müşir Liman von Sanders'e Osmanlı Ordusunda Alman Askeri Heyetleri. OTAM Ankara Üniversitesi Osmanl Tarihi Araştırma ve Uygulama Merkezi Dergisi, 4, 297-307. Doi: 10.1501/OTAM_0000000329.

Pierer, H. A. (1857-1865). Universal-Lexikon der Vergangenheit und Gegenwart (Cilt 1-19). Altenburg: H. A. Pierer. http://www.zeno.org/Pierer-1857 (Erişim: 05 Ekim 2018).

Sanders, L. v. (1999). Türkiye’de Beş Yıl 1. Örgün Uğurlu (Çev.). İstanbul: Cumhuriyet Gazetesi Yeni Gün Haber Ajansı.

Şahin, T. E. (2014). Yolun Tarihi ve Yol Kültürü I, Akra Kültür Sanat ve Edebiyat Dergisi, 4, 7-28.

Tosun, M. (2013, 02 Aralık). İlk Adım Böyle Atılmıştı. Hürriyet Gazetesi. http://www.hurriyet.com.tr/ilk-adim-boyle-atilmisti-25258183 (Erişim: 17 Ekim 2018).

Türk Dil Kurumu. Güncel Türkçe Sözlük. http://www.tdk.gov.tr/index.php?option=com_gts (Erişim: 05 Ekim 2018).

. Kişi Adları Sözlüğ̈̈̈. http://www.tdk.gov.tr/index.php?option=com_kisiadlari (Erişim: 05 Ekim 2018).

(1974). Tarih Terimleri Sözlügü. Büyük Türkçe Sözlük. http://www.tdk.gov.tr/index.php?option=com_bts (Erişim: 05 Ekim 2018).

Wissen. Großes Wörterbuch der Deutschen Sprache Rechtschreibwörterbuch. http://www.wissen.de/lexikonsuche/lexicon/all (Erişim: 05 Ekim 2018).

Wahrig, G. Wahrig Fremdwörterlexikon. http://www.wissen.de/lexikonsuche/fwl/all (Erişim: 05 Ekim 2018).

Zengin, E. (2013). Türk-Alman İlişkilerinde Türk İmajını Meydana Getiren Olgular ve Eserlere Yansıması. CBÜ Sosyal Bilimler Dergisi, 11/1, 48-57. 